\title{
Automatic detection of ship tracks in ATSR-2 satellite imagery
}

\author{
E. Campmany ${ }^{1, *}$, R. G. Grainger ${ }^{1}$, S. M. Dean ${ }^{1, * *}$, and A. M. Sayer ${ }^{1}$ \\ ${ }^{1}$ Atmospheric, Oceanic and Planetary Physics, University of Oxford, Oxford OX1 3PU, UK \\ * now at: NASA Goddard Institute for Space Studies, New York, USA \\ *** now at: National Institute of Water and Atmospheric Research Ltd, Wellington, New Zealand
}

Received: 30 May 2008 - Published in Atmos. Chem. Phys. Discuss.: 1 August 2008

Revised: 11 February 2009 - Accepted: 26 February 2009 - Published: 18 March 2009

\begin{abstract}
Ships modify cloud microphysics by adding cloud condensation nuclei $(\mathrm{CCN})$ to a developing or existing cloud. These create lines of larger reflectance in cloud fields that are observed in satellite imagery. An algorithm has been developed to automate the detection of ship tracks in Along Track Scanning Radiometer 2 (ATSR-2) imagery. The scheme has been integrated into the Global Retrieval of ATSR Cloud Parameters and Evaluation (GRAPE) processing chain. The algorithm firstly identifies intensity ridgelets in clouds which have the potential to be part of a ship track. This identification is done by comparing each pixel with its surrounding ones. If the intensity of three adjacent pixels is greater than the intensity of their neighbours, then it is classified as a ridgelet. These ridgelets are then connected together, according to a set of connectivity rules, to form tracks which are classed as ship tracks if they are long enough. The algorithm has been applied to two years of ATSR-2 data. Ship tracks are most frequently seen off the west coast of California, and the Atlantic coast of both West Africa and SouthWestern Europe. The global distribution of ship tracks shows strong seasonality, little inter-annual variability and a similar spatial pattern to the distribution of ship emissions.
\end{abstract}

\section{Introduction}

\subsection{ATSR-2 and GRAPE}

The Along Track Scanning Radiometer 2 (ATSR-2) is on board a low Earth orbit satellite at a height of about $780 \mathrm{~km}$, performing approximately 14 orbits in one Earth day (Mutlow, 1999). The instrument measures at near-nadir angles of up to $22^{\circ}$, and in a forward-view at about $55^{\circ}$. In the case of

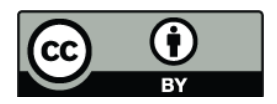

Correspondence to: E. Campmany (ecampmany@giss.nasa.gov) the nadir view, used in this study, the scan swath is 575 pixels, with a nominal pixel size of $1 \mathrm{~km}$ by $1 \mathrm{~km}$ at the centre of the swath. This leads to every point on the Earth's surface being mapped nominally ten times a month. The channels in which radiance is measured are $0.55 \mu \mathrm{m}, 0.67 \mu \mathrm{m}, 0.87 \mu \mathrm{m}$, $1.6 \mu \mathrm{m}, 3.7 \mu \mathrm{m}, 10.8 \mu \mathrm{m}$ and $12 \mu \mathrm{m}$ (referred to as channels 1 to 7 , respectively).

The Global Retrieval of ATSR Cloud Parameters and Evaluation (GRAPE) project has produced a global cloud and aerosol data set from the entire ATSR-2 mission (1995-2001 at present). Version 3 of the data set has now been produced, with many improvements over earlier versions, and it is accessible from the British Atmospheric Data Centre (BADC). The analysis has been performed using the Oxford/RAL Aerosol and Cloud (ORAC) optimal estimation retrieval scheme. The data set includes the following parameters on an orbit by orbit basis (at $3 \times 4 \mathrm{~km}$ resolution) and as coarser resolution $\left(1^{\circ} \times 1^{\circ}\right.$ or $\left.2.5^{\circ} \times 2.5^{\circ}\right)$ monthly means (along with error estimates for each value): cloud fraction, cloud phase (water or ice), cloud top temperature, cloud top pressure, cloud top height, cloud optical depth (at $0.55 \mu \mathrm{m}$ ), cloud effective radius, cloud liquid water path, skin temperature, aerosol optical depth (at $0.55 \mu \mathrm{m}$ ), aerosol effective radius and surface albedo at $0.55 \mu \mathrm{m}$. Validation of cloud and aerosol properties derived using the GRAPE algorithm is ongoing (Thomas et al., 2007; Campmany et al., 2007). The ship track detection algorithm has been applied to the GRAPE Level 2 radiances with an approximate resolution of $12 \mathrm{~km}^{2}$ formed by averaging $3 \times 4$ ATSR- 2 instrument $(1 \times 1 \mathrm{~km})$ pixels.

\subsection{Ship tracks}

The properties of ship tracks vary widely and they have been investigated by various studies: Coakley et al. (1987); Albrecht (1989); Platnick and Twomey (1994); Ferek et al. (1998); Coakley and Walsh (2002); Schreier et al. (2006).

Published by Copernicus Publications on behalf of the European Geosciences Union. 
The most extensive of these was the Monterey Area Ship Track (MAST) experiment which combined in situ measurements with satellite imagery from the Advanced Very High Resolution Radiometer (AVHRR). The MAST experiment studied ship tracks for one month off the coast of California. The results gained from the analysis of 131 ship tracks produced by known ships showed that the average ship track had length $296 \pm 233 \mathrm{~km}$ and width $9 \pm 5 \mathrm{~km}$ (Durkee et al., 2000a). Ship tracks are rarely found in cloud at an altitude above $1 \mathrm{~km}$ (Coakley et al., 2000). Thus ship tracks have the potential to cover a large area and effect the Earth's climate. Quantification of this effect requires a knowledge of the global frequency of occurrence of ship tracks and so motivates this work. The results of the MAST experiment showed that ship tracks have a wide range of optical properties. The contrast between the optical properties of ship tracks and those of unpolluted background cloud was also shown to vary. The average ambient cloud reflectance in AVHRR $3.7 \mu \mathrm{m}$ channel was $11 \pm 4 \%$ while the ship track reflectance at the same wavelength was $14 \pm 5 \%$. The difference in optical properties varied not only between ship tracks but also along the lengths of individual tracks on a scale of $1 \mathrm{~km}$ to $25 \mathrm{~km}$. The MAST results showed a significant difference in all the examined properties of ship tracks. This makes the development of a method of automated detection very difficult. Without an exact definition of a ship track it is hard to invent a method of selecting them from an image, especially when a ship track is embedded within background cloud.

It is hypothesised that certain background environmental conditions need to be in place before the formation of ship tracks can occur (Durkee et al., 2000b). These conditions include a small boundary layer depth, pre-existing cloud formation mechanisms, and CCN concentrations below a threshold value. The MAST study returned average values of wind speed of $7.8 \mathrm{~ms}^{-1}$, surface pressure of $1018.3 \mathrm{mb}$ and surface temperature of $287.8 \mathrm{~K}$ (Durkee et al., 2000a).

Albrecht (1989) proposed one further effect ship tracks could have on cloud cover, and hence the climate: a reduction in drizzle. An increase in $\mathrm{CCN}$ concentrations, as already seen, reduces the size of cloud droplets. This in turn decreases the probability of cloud droplets colliding and hence growing to the size required for them to fall as precipitation. The ultimate effect of this is to increase the lifetime of clouds, further increasing the albedo effect of ship tracks.

\section{Algorithm description}

The problem of ship track detection is similar to the contrail (condensation trail) detection problem since both are formed as a result of an increase in CCN. However contrails form as cirrus cloud in the upper atmosphere. There are several existing methods to detect contrails, based on straight line detection using Hough transforms relying on the fact that jet aircraft mainly fly in straight lines at speeds sufficient to create linear ridges in visible satellite images. However, straight line detection is less appropriate in the case of ship tracks, which are formed over longer scales. The age of a ship track is $7.3 \pm 6.0 \mathrm{~h}$ (Durkee et al., 2000a), a time-scale which allows for significant distortion by dispersion and geostrophic effects. It is therefore unsurprising that less work has been done on the automated detection of ship tracks.

The algorithm firstly identifies intensity ridgelets in clouds which have the potential to be part of a ship track. This identification is done by comparing each pixel with its surrounding ones. If the intensity of three adjacent pixels is greater than the intensity of its neighbours, then it is classified as a ridgelet. These ridgelets are then connected together, according to a set of connectivity rules, to form tracks (the continuation of the track is allowed in the co-linear, parallel or 45 degrees direction), and finally are classed as ship tracks if they are long enough. The algorithm includes adjustable parameters: pixel spacing, minimum intensity and track length that will be tuned in Sect. 2.4.

\subsection{Filtering}

For computational efficiency images are screened using the $12 \mu \mathrm{m}$ brightness temperature images before applying the ship track detection algorithm. This is done by comparing the observed $12 \mu \mathrm{m}$ brightness temperature with the calculated clear sky $12 \mu \mathrm{m}$ brightness temperatures produced by the Radiative Transfer for TOVS (RTTOV) algorithm (Saunders et al., 1999) applied to European Centre for Mediumrange Weather Forecasting (ECMWF) reanalysis data. Since the tracks only occur at low altitude the brightness temperature of tracks seen by the satellite will be close to that of the surface. The rate of change of temperature with height (the atmospheric lapse rate) close to the Earth's surface is about $6.5 \mathrm{~K} \mathrm{~km}^{-1}$ (Stephens, 1994). Given that the tracks form in the boundary layer, mostly well below $1 \mathrm{~km}$, and allowing for diurnal temperature variation and errors, suggested that there is potential for ship track formation only in clouds whose temperatures are within $10 \mathrm{~K}$ of the surface temperature. This criterion was used to eliminating those pixels containing higher cloud from analysis.

In $1.6 \mu \mathrm{m}$ channel images, cloud-covered areas show up as areas of higher intensity compared to the ocean surface. It is therefore reasonable to set a lower limit on the intensity of pixels which are to be considered. In the algorithm this is done by setting a parameter for the lower limit, relative to the median pixel intensity for the orbit from which the image is taken. By using exactly the median value it can be said that half the pixels will be automatically discounted.

\subsection{Ridge detection}

Initially pixels are analysed individually in relation to the pixels surrounding them to determine whether or not they 

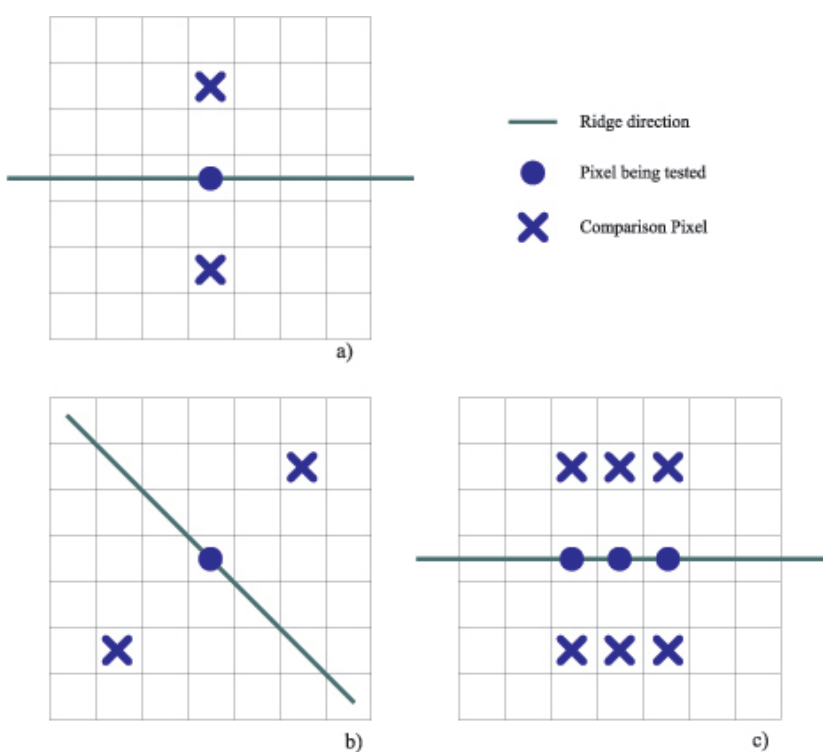

Fig. 1. Pixel orientation test for: (a) horizontal alignment, (b) a diagonal alignment. The net test geometry for a horizontal ridgelet is shown in (c). The comparison pixels must be less intense than the corresponding test pixel for classification to be made.

could be part of a ridge segment in any of four orientations. These are the vertical, horizontal and two diagonals with respect to the image.

The pixel's intensity is analysed relative to comparison pixels at a specified spacing in the appropriate direction to determine whether or not its intensity is greater; the geometry of this is shown in Fig. 1. Here the situation is one with a comparison pixel either side at a pixel spacing of two. The use of one pixel either side was envisaged but the algorithm allows for a second to be specified. The analysis leads to four arrays of information, one for each orientation, to specify which pixels have met the criteria to potentially form part of a ridgelet (line segment) in the corresponding directions.

The $1.6 \mu \mathrm{m}$ channel intensity, as a continuous variable input, will satisfy the ridge pixel criteria quite often even for relatively featureless areas of cloud. It is therefore useful to define a minimum intensity difference between the test pixel and the comparison pixels that must be exceeded in order to make the classification. In the code this was set with reference to the median pixel intensity.

Ridgelets are defined by the algorithm as three adjacent pixels, satisfying the criteria in for a given direction. An example is shown in Fig. 1c for a horizontal ridgelet. By scanning the image for such groupings this refined information can be stored in four arrays (one for each orientation). This was done by recording the centre pixel of each such $1 \times 3$ pixel rideglet in the array for the appropriate orientation. This gives a method of approximating image structure, which may not be straight, to a series of straight line segments. It also retains the information about the sense in which they are orientated.

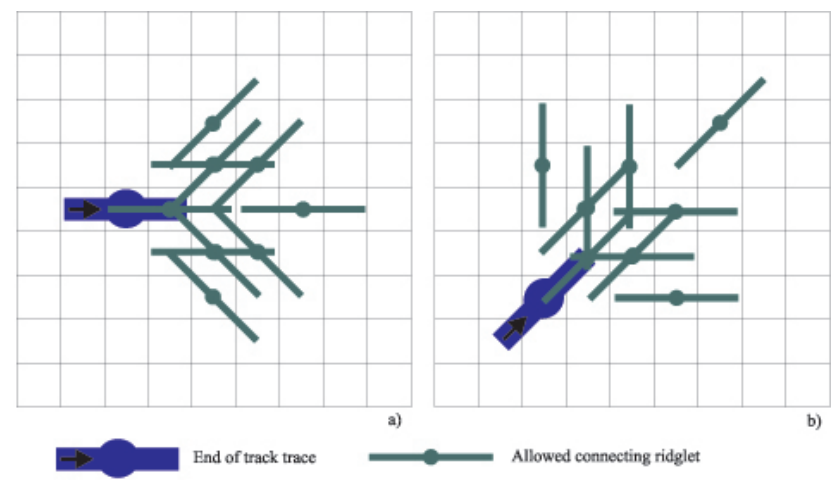

Fig. 2. The connectivity rules for progressing the trace of a track. (a) shows this for a horizontal segment tracing from the left, (b) shows this for a diagonal segment coming up from the left.

\subsection{Track classification}

With rideglets defined from a filtered set of pixels the algorithm has a basis from which to find longer sections of ridge. The method used consists of a set of connectivity rules: from each ridgelet pixel the surrounding pixels are examined to determine whether or not any other ridgelet pixels are located such that they may reasonably form part of the same ridge. If an appropriate ridgelet exists the algorithm then traces along to it and searches for more ridgelets according to the same set of rules.

Allowed continuation ridgelets for the tracing are shown in Fig. 2. With $4(1 \times 3$ pixel $)$ ridgelet types defined this leads to 8 different track end situations to be accounted for in the connectivity rules, i.e. each ridgelet could be followed by the code in both end tracks. The general rule applied was that part of a ridge could turn by up to 45 degrees in the image between ridgelets. It was also deemed acceptable that gaps could be jumped when tracing ridges, provided the ridge segment continued in a straight line along the image from the previous ridgelet. Figure 2 shows this for a horizontal ridgelet and a diagonal one; rotations of these apply for the other six track directions.

The algorithm traces a track until it reaches a dead end, this being where it cannot find another ridgelet to which it can connect. Up to this point the path taken from the start pixel is recorded so that at the end of the trace it can be decided whether or not to retain the track. In theory the best criterion in deciding whether or not to retain a trace, and mark an area as ship track, is length. This could be done on pixel count, but to speed computation it was based on iterations through the connectivity rules. This gives a higher weighting for a continuing straight line segment than one with the same number of pixels which changes in direction. This is because when tracing along a straight line the jump between ridgelet centres for each iteration is only one pixel, hence increasing the number of pixels in the track by 1 for each iteration rather 

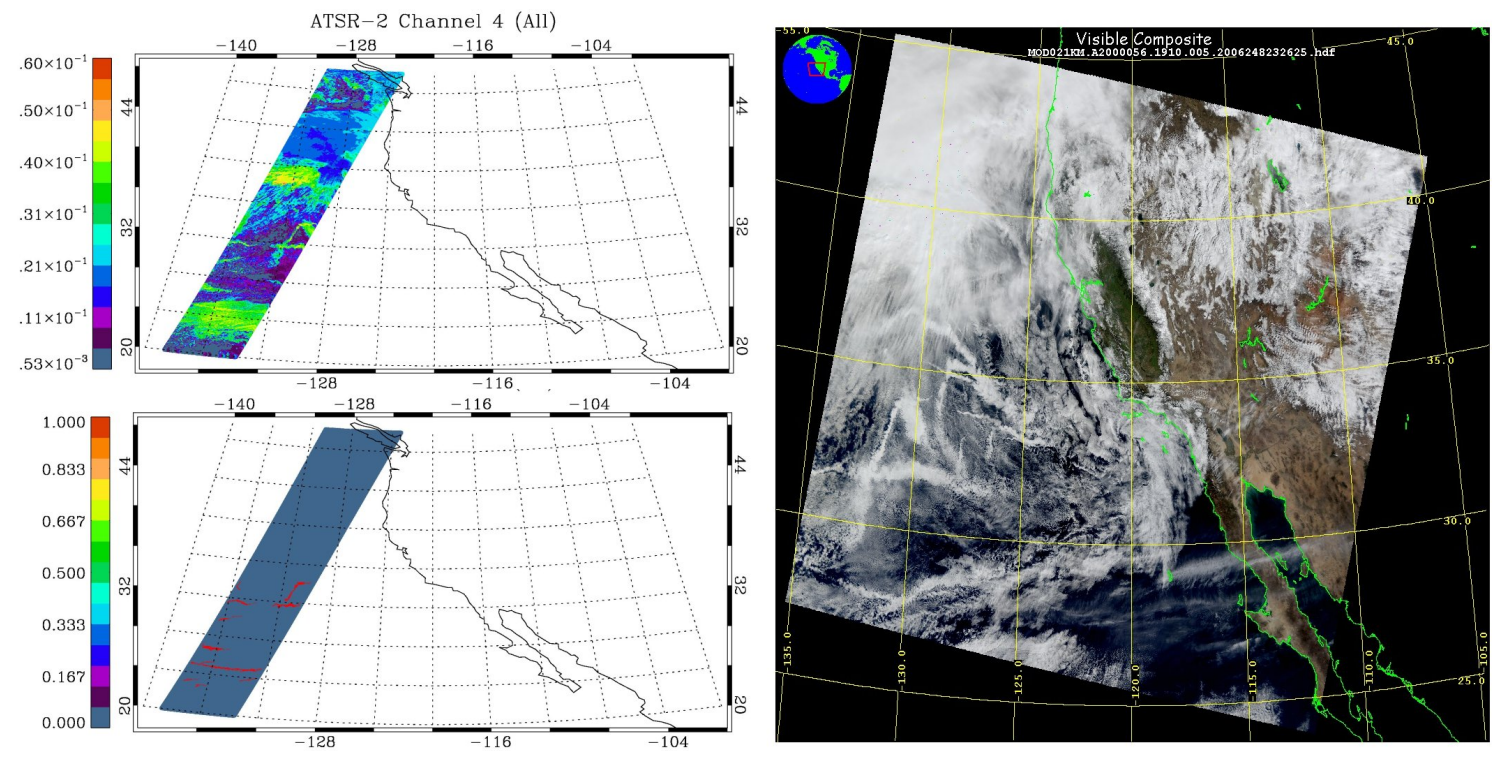

Fig. 3. Example of scene with ship tracks on 25 February 2000, off the coast California. Top-left: ATSR-2 Channel Channel 4. Bottom-left: Ship track mask detected. Right: MODIS image false colour.
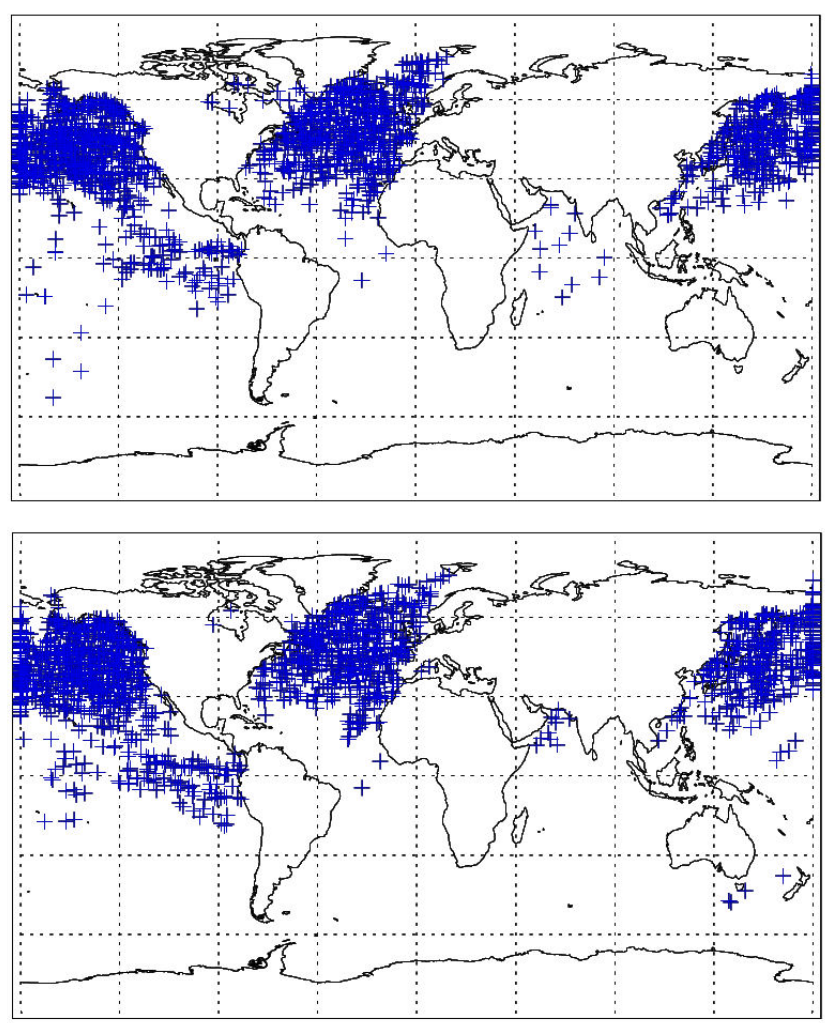

Fig. 4. Global distribution of ship tracks as detected with the algorithm of ATSR-2 images for the years 1999 (top) and 2000 (bottom). than 2 or 3, as can be seen in Fig. 2. However, since tracks are generally locally straight this was seen as no disadvantage.

\subsection{Sensitivity study}

A number of parameters in the algorithm were varied to tune it to identify confirmed ship tracks. Effectively a parameter was varied until a best match was obtained between pixels automatically identified as ship tracks and those identified by eye using the $1.6 \mu \mathrm{m}$ channel.

\subsubsection{Pixel spacing}

The brightness comparison test requires a ship track to be brighter than the surrounding unperturbed cloud yet not so far away as to capture natural spatial variation in cloud brightness. As ship tracks may easily be up to $15 \mathrm{~km}$ or more wide in places the nearest "background" pixel was varied from perpendicular spacing of between 2 and 6 superpixels $(3 \times 4$ instrument pixels) to see which recorded the track width best. The optimum spacing chosen for use was 5 super-pixels.

\subsubsection{Minimum intensity}

The minimum intensity filter was applied with a view to cutting out some of the noise from within regions of lower reflectance, which do not have significant cloud cover. This filter was varied between the median value of the pixel intensity in the orbit and two times the median. A value of 1.5 times the median albedo was chosen as this minimized the background noise. 

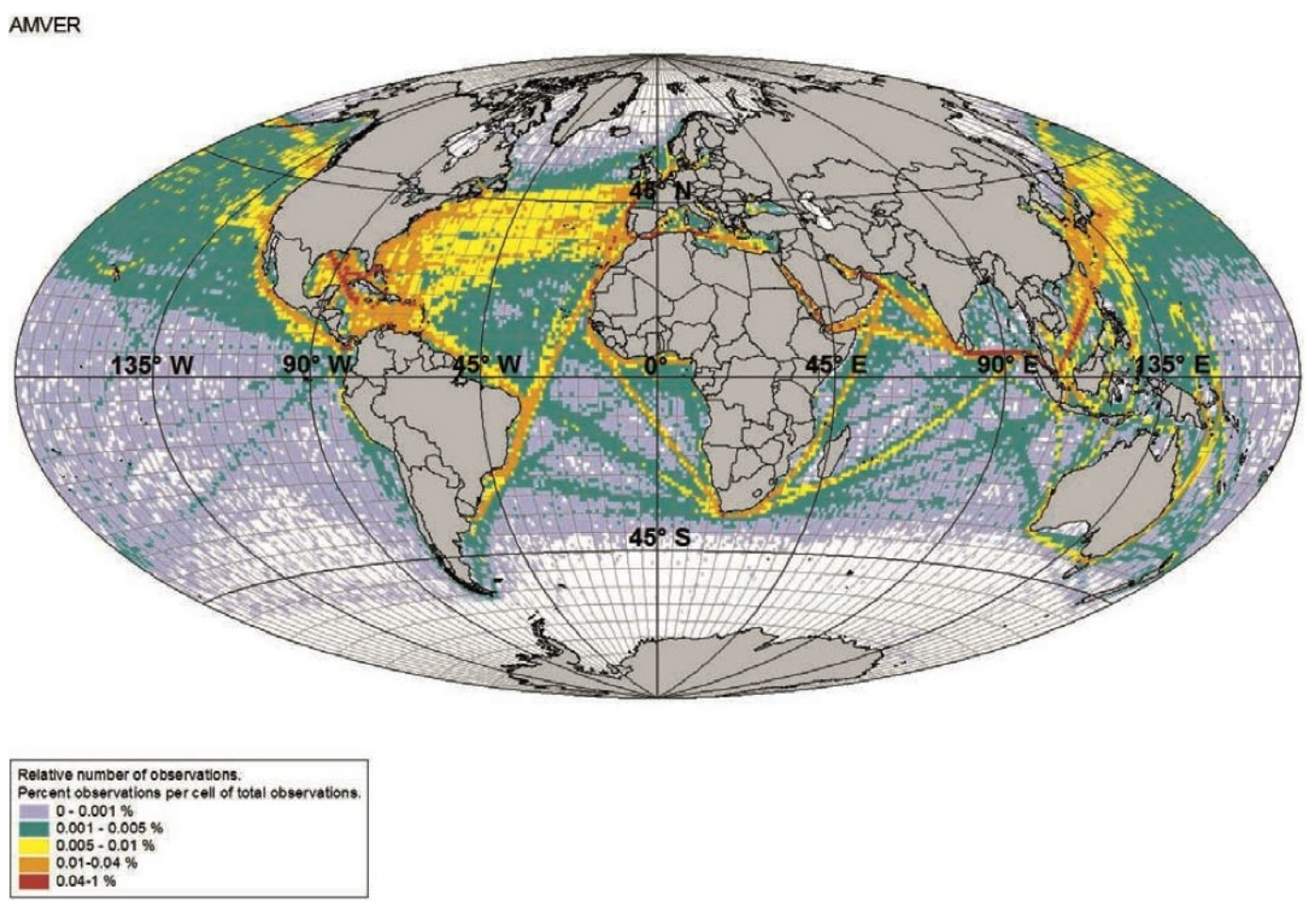

Fig. 5. Global distribution of $\mathrm{NO}_{\mathrm{x}}$ emissions for different ship types (adapted from Endresen et al. 2003).

\subsubsection{Track length}

Varying the minimum track length gave a best response at 20 iterations through the connectivity conditions.

\section{Algorithm application}

\subsection{Validation}

To make an estimate of the the algorithm accuracy the authors manually inspected 81 orbits from April 1999 in which ship tracks had been identified. Of these, 59 were seen to have ship tracks, and 17 were false positives. In the remaining 5 cases it was not clear whether the identification was correct or not. Dependent on whether these ambiguous images are assumed to have contained ship tracks or not leads to a rate of between $21 \%$ and $27 \%$ false positives.

The majority of false detections corresponded to images with a low number of pixels flagged as ship tracks. Conversely, tracks detected by the algorithm and confirmed by eye tended to be clustered. This suggests that a threshold to help find false positives may be based on the number of retrieval pixels detected as ship tracks. The explanation for this is that shipping lanes are well-used, so if conditions are right to generate a track from one ship then it is likely that nearby there will be more ships whose exhausts may generate tracks.

\subsection{Statistical Analysis}

The algorithm has been applied to two years of ATSR-2 data (1999 and 2000). In total, 4360 orbits were analyzed and 1924 ship tracks were detected. Figure 3 shows an example of a ship track detected. The scene is from 25 February 2000 and ships tracks can be clearly seen in a MODIS satellite image of the area, taken on the same day. The image, which is a false colour composite based on three channels, shows a large number of tracks, in a region of cloud, off the coast of California. On the left an image of the ATSR-2 $1.6 \mu \mathrm{m}$ channel taken at approximately the same time, and at the bottom the result of applying the algorithm.

In order to visualize the global distribution of ship tracks, the coordinates of the detected tracks have been plotted in Fig. 4 for both years. Most of the tracks are located in the North Pacific and Atlantic oceans, while in the Southern Hemisphere there are hardly any tracks. There are no main differences between different years. The plots look quite similar to the global distribution of $\mathrm{NO}_{\mathrm{x}}$ emissions from ships presented by Endresen et al. (2003) (see Fig. 5). There are also previous studies of global distribution of ship tracks from satellite imagery that obtain very similar results (Schreier et al., 2007).

The results can also be presented distributed by latitude and by month to study the seasonal and latitudinal patterns (Fig. 6). The seasonal variation is strong in both years 

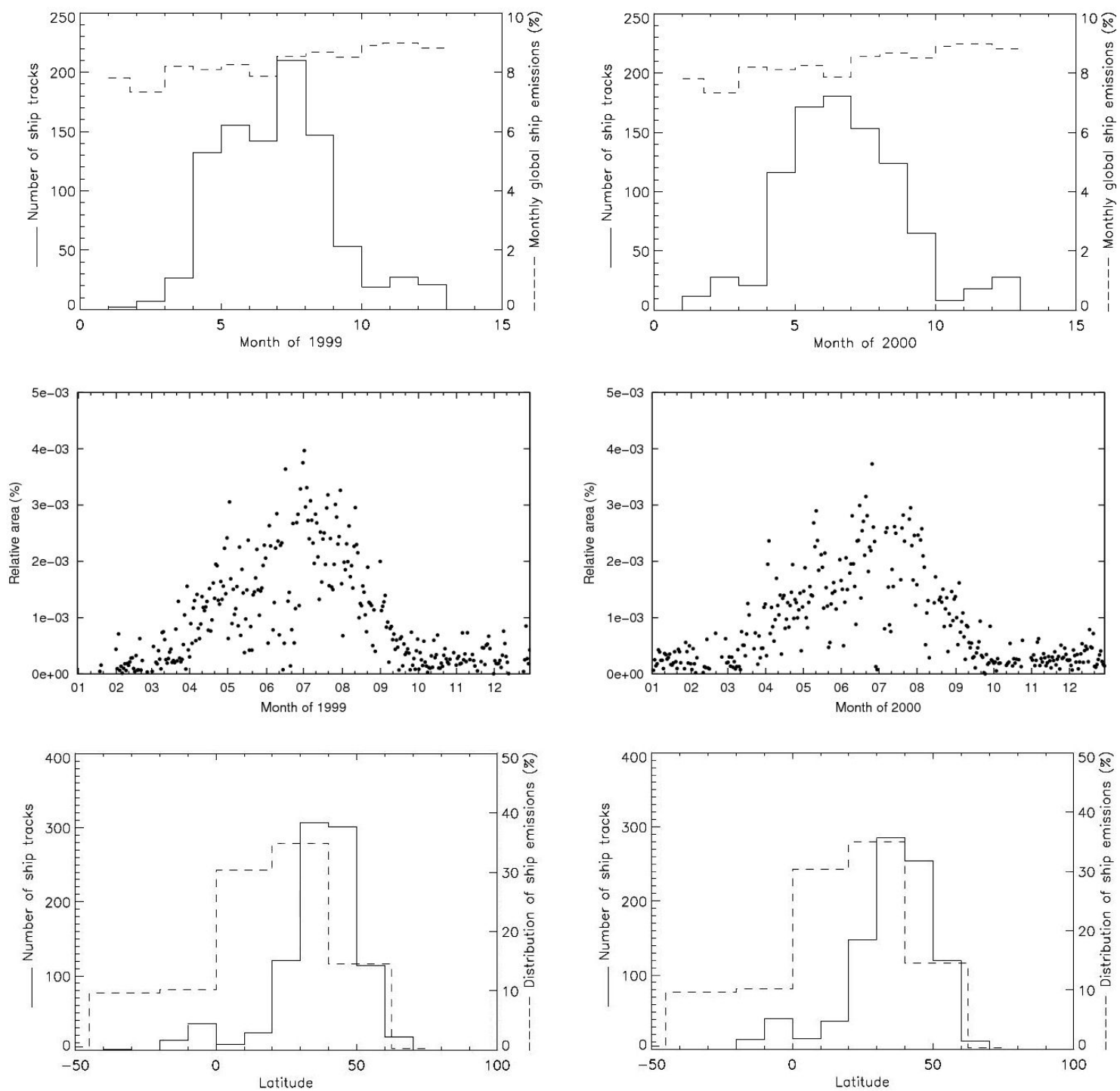

Fig. 6. Monthly (top) and latitudinal (bottom) distribution of ship tracks compared with vessel traffic for 1999 (left) and 2000 (right). The relative area of ship tracks distributed by month is also shown (centre).

showing a maximum in boreal summer. The annual distribution of relative area of ship tracks shows similar pattern, with a maximum area of $4 \times 10^{-3} \%\left(4 \times 10^{5} \mathrm{~km}^{2}\right)$. The area is calculated computing all the pixels marked as a track and the relative ratio is determined by dividing by the total area of the orbit. The values showed in Fig. 6 correspond to data integrated for the whole day. As the seasonal distribution of vessel traffic, extracted from Corbett et al. (2007), hardly presents a seasonal cycle it is apparent that ship track occurrence is strongly modulated by meteorological conditions. The latitudinal distribution shows a higher frequency of ship tracks for latitudes between 30 and $60^{\circ} \mathrm{N}$. Compared with the vessel traffic data given by Endresen et al. (2003), it can be appreciated that the pattern is roughly the same.

\section{Conclusions}

An algorithm to detect ship tracks has been described and applied. Initially the algorithm identifies intensity ridgelets in clouds which have the potential to be part of a ship track. These ridgelets are then connected, according to a set of connectivity rules, to form tracks and are finally classed as ship tracks if they are long enough. The algorithm has been applied to two years of ATSR-2 data by processing 4360 orbits. One thousand nine hundred and twenty four tracks were detected, showing a global distribution similar to the ship emissions distribution with a maximum occurrence in the north Pacific and Atlantic. An improvement of the algorithm could be implemented in a future by using the microphysical 
properties retrieved by the GRAPE algorithm as new conditions for the detection of ship tracks.

Acknowledgements. The authors would like to thank Daniel White for his help in developing and coding the algorithm and the two anonymous referees for their critical and constructive comments for improving the manuscript. This work has been supported by the QUANTIFY project which is funded by the European Commission within the 6 th research framework programme.

Edited by: J. Quaas

\section{References}

Albrecht, B. A.: Aerosols, cloud microphysics and fractional cloudiness, Science, 245, 1227-1230, 1989.

Campmany, E., Thomas, G., Carboni, E., Poulsen, C., Grainger, R., Lawrence, B., and Watts, P.: Initial results from the GRAPE version 2 aerosol and cloud climatology, in: Geophysical Research Abstracts, 9, p. 04376, 2007.

Coakley, J. A. and Walsh, C. D.: Limits to the aerosol indirect radiative effect derived from observations of ship tracks, J. Atmos. Sci., 59, 668-680, 2002.

Coakley, J. A., Bernstein, R. L., and Durkee, P. A.: Effect of shipstack effluents on cloud reflectivity, Science, 237, 1020-1022, 1987.

Coakley, J. A., Durkee, P., Nielsen, K., Taylor, J., Platnick, S., Albrecht, B., Babb, D., Chang, F., Tahnk, W., Bretherton, C., and Hobbs, P.: The Appearance and Disappearance of Ship Tracks on Large Spatial Scales, J. Atmos. Sci., 57, 2765-2778, 2000.

Corbett, J. J., Wang, C., Winebrake, J., and Green, E.: Allocation and Forecasting of Global Ship Emissions, Tech. rep., Clean Air Task Force, Boston, MA, USA, 2007.
Durkee, P. A., Chartier, R., Brown, A., Trehubenko, E., Rogerson, S., Skupniewicz, C., Nielsen, K., Platnick, S., and King, M.: Composite Ship Track Characteristics, J. Atmos. Sci., 57, 2542-2553, 2000a.

Durkee, P. A., Noone, K. J., and Bluth, R. T.: The Monterey Area Ship Track Experiment, J. Atmos. Sci., 57, 2523-2541, 2000 b.

Endresen, O., Sørgard, E., Sundet, J. K., Dalsøren, S. B., Isaksen, I. S., Berglen, T. F., and Gravir, G.: Emission from international sea transportation and environmental impact, J. Geophys. Res., 108(D17), 4560, doi:10.1029/2002JD002898, 2003.

Ferek, R. J., Hegg, D. A., Hobbs, P. V., Durkee, P., and Nielsen, K.: Measurements of ship-induced tracks in clouds off the Washington coast, J. Geophys. Res., 206, 23199-23206, 1998.

Mutlow, C.: ATSR-1/2 User Guide, 1.0 edn., 1999.

Platnick, S. and Twomey, S.: Determining the Susceptibility of Cloud Albedo to Changes in Droplet Concentration with the Advanced Very High Resolution Radiometer, J. Appl. Meteorol., 33, 334-347, 1994.

Saunders, R., Matricardi, M., and Brunel, P.: An improved fast radiative transfer model for assimilation of satellite radiance observations, Q. J. Roy. Meteor. Soc., 125, 1407-1425, 1999.

Schreier, M., Mannstein, H., Eyring, V., and Bovensmann, H.: Global ship track distribution and radiative forcing from 1 year of AATSR data, Geophys. Res. Lett., 34, L17814, doi:10.1029/ 2007GL030664, 2007.

Schreier, M., Kokhanovsky, A. A., Eyring, V., Bugliaro, L., Mannstein, H., Mayer, B., Bovensmann, H., and Burrows, J. P.: Impact of ship emissions on the microphysical, optical and radiative properties of marine stratus: a case study, Atmos. Chem. Phys., 6, 4925-4942, 2006, http://www.atmos-chem-phys.net/6/4925/2006/.

Stephens, G. L.: Remote Sensing of the Lower Atmosphere, Oxford University Press, chap. 1, 3-33, 1994.

Thomas, G. E., Poulsen, C. A., Curier, R. L., Lewuw, G., Marsh, S. H., Carboni, E., Grainger, R. G., and Siddans, R.: Comparison of AATSR and SEVIRI aerosol retrievals over the Northern Adriatic, Q. J. Roy. Meteor. Soc., 133, 85-95, 2007. 